\title{
The Influence of Culture on Trade between China and Southeast Asia: Based on the Perspective of "Belt and Road"
}

\author{
Song Yanan \\ School of Business \\ Macau University of Science and Technology \\ Macau, China \\ ynsong@must.edu.mo
}

\begin{abstract}
This paper analyzes the influence of culture on China's bilateral trade to show the influence of the construction of "Belt and Road Initiative" by using data of 11 Southeast Asian countries from 2000 to 2015 . The results show that culture factors, common language, common policy institution and cultural intimacy have significant positive impact on bilateral trade, while distance shows the negative impact on bilateral trade. The various cultural factors have different degrees of impact on trade. Based on the findings, this paper pointed out that, in order to promote the trade development along the "Belt and Road" countries and to balance the trade surplus, we should vigorously promote the construction of cultural exchange platform among trade partners.
\end{abstract}

Keywords-Culture; Bilateral Trade; China; Southeast Asia; Gravity Model; Belt and Road

\section{INTRODUCTION}

In September and October of 2013, when China's General Secretary Xi Jinping visited Southeast Asia and Central Asian countries, he proposed the strategic concept of jointly building the "New Silk Road Economic Belt" and "21st Century Maritime Silk Road". In the "Vision and Actions on Jointly Building Silk Road Economic Belt and 21st-Century Maritime Silk Road", Xi Jinping pointed out that the construction of the "Belt and Road Initiative" is based on the principle of mutual consultation, joint construction, and sharing. It is an open and inclusive economic system. Then there is a country solo but an ensemble of countries along the line. The document also pointed out the policy coordination, facilities connectivity, unimpeded trade, financial integration and people-to-people bonds as five major goals.

How to foster the people-to-people bonds? The foundation is to build a convenient cultural exchange platform to promote trade cooperation. In the era of economic globalization, the development of an open economy has slowly become the mainstream of most countries, and the trade in cultural products and cultural exchanges has become a driving force for promoting bilateral trade. As China's economy continues to transform and upgrade, the importance of cultural factors in the promoting an open economic system have exceeded the basic production factors such as the labor force and natural resources.
During the economic globalization, the culture factors continuously achieves a remarkable effect in promoting trade between countries. The higher the cultural interdependence between two countries, then people in both countries will have easier acceptance of the products produced by the other country. Besides the trade of culture products, tourism is the most direct way of cultural exchange and create the culture proximity and intimacy. Tourism can not only allow visitors to understand the local culture and create the cultural approval, but also be attracted by the local products. It is also possible to realize the commonality among the citizens in the countries along the "Belt and Road" regions. Chinese traditional culture built an important bridge for the communication and attraction for China's global trade. Therefore, this paper intend to study the culture influence on bilateral trade to show the culture influence of trade under the construction of "Belt and Road Initiative".

\section{Methodology}

The gravity model of international trade was first formulated by Dutch economist Jan Tinbergen in 1962 and since then a large body of work regarding the theoretical and practical considerations has been written. Initially, the model came under criticism for its lack of theoretical underpinning, but authors such as Bergstrand have been able to marry more typical consumer demand theory with the gravity framework and show that the gravity equation is a reduced form of Heckster-Ohin demand models. In fact, the model can be backed up with a variety of underlying theoretical structures.

The basic gravity model has been an extremely successful empirical representation of international trade flows. The basic model put forward by Tinbergen posits that the flow of trade between two countries is a function of the GDP of each and the distance between them. Equation (1) takes the same form as Newtonian gravity, but replaces mass with an of flows may be represented here. Notable is the addition of which represents an error term that is independent and identically distributed economic interpretation: GDP. Tinbergen's flow was the value traded goods, but many types 


$$
\text { Flow }_{i j}=\alpha \frac{G D P_{i}^{\beta_{1}} \times G D P_{j}^{\beta_{2}}}{D i s \tan c e_{i j}^{\beta_{3}}} \eta_{i j}
$$

In order to estimate eq. (1) using OLS, Tinbergen applied a simple log-linearization, see eq. (2) In this way the parameters $\alpha, \beta 1, \beta 2$ and $\beta 3$ can be determined. Because the equation takes the natural logarithm of both sides, the resulting coefficients can be interpreted as elasticities, which are conveniently unitfree.

$$
\ln F \text { low }_{i j}=\ln \alpha+\beta_{1} \ln G D P_{i}+\beta_{2} \ln G D P_{j}+\beta_{3} \ln D i s \tan c e_{i j}+\eta_{i j}
$$

Using the above estimation it has been shown that there is a positive correlation between GDP and the flow of exports. Distance is negatively correlated with flows, and there are many dimensions to distance that have been shown to be important. For example DeGroot et al show the importance of cultural distance using Hoftetters metrics, and in Guiso et al the importance of common language is clear [1].

Linnemann (1966) added population variables to the gravity model and indicated that the size of the population is positively related to the scale of trade [2]. And Bergstrand (1985) replaced population by per capita income as a variable [3].

With the development study of gravity models for trade, Soloaga and Winters (1999) [4], Piani and Kume (2000), and Lucian Cermal (2001) added different regional FTA to the equations. Straubhear (1991) [5] proposed that cultural intimacy are a function of a combination of common language, geographic distance, and history of cultural trade. Zang Xin, Lin Zhu, and Shao Jun (2012) [6] conducted an extended study on cultural intimacy on the basis of Straubhear (1991), which showed the influence on economic development.

In addition to Straubhaar (1991), there are some scholars who have a certain measure of cultural intimacy, such as Guiso. et al (2009) [7] uses bilateral trust variables, Melitz (2008) uses language approximation [8], Wagner et al.(2002)uses immigration variables [9], Rose (2000) uses past colonial connections [10], and so on. This paper will measure the cultural intimacy by institutional distance, common language, and world tourism heritages.

\section{DATA}

Based on Anderson (2001) developed, the model of this paper is

$$
\begin{aligned}
M_{i j} & =\left(\frac{Y_{i} Y_{j}}{Y_{w}}\right)\left(\frac{T_{i j}}{P_{i} P_{j}}\right)^{1-\sigma} \\
T_{i j} & =\prod_{i=1}^{m} D_{i}^{\gamma m} \times \exp \left(\sum_{k=1}^{n} \gamma_{k} V_{i j}\right)
\end{aligned}
$$

According to the previous research results and the variables needed in this paper, the final expansion of the gravitational equation is as follows:

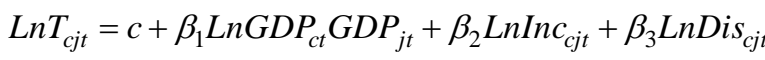

$$
\begin{aligned}
& +\beta_{4} C I_{c j t}+\beta_{5} A P E C+\beta_{6} L a n+\beta_{7} \text { Bor }+\mu
\end{aligned}
$$

In the eq. (5), Tcj indicates the bilateral trade volume between China and country j; GDPc and GDPj indicate China's GDP and the GDP of country $\mathrm{j}$; Discj indicates the distance between the capitals of China and country $j$; CIcj indicates the cultrual intimacy measured by number of the world heritage in China. Lancj indicates whether China and $\mathrm{j}$ have a common language; Borcj indicates whether China and Country $\mathrm{j}$ have common borders; APEC indicates whether China and $\mathrm{j}$ are members of APEC; and Inccj indicates the difference in per capita income between China and country $\mathrm{j}$.

For Southeast Asia, the "21st Century Maritime Silk Road" mainly involves 11 countries along the route. This paper selects data of these 11 countries from 2000-2015 including Singapore, Malaysia, and Indonesia etc. to conduct panel Gravity model analysis to explain the impact of cultural influence on bilateral trade. In the paper, the data of the bilateral trade between the two countries are collect from the China Statistical Yearbook; GDP data are from the World Bank; the geographical distance data are obtained through the world latitude and longitude query system; the Chinese cultural heritage data are collected from the World Heritage Centre of UNESCO; and others are dummy variables.

TABLE I. PANEL UNIT RoOT TEST

\begin{tabular}{|c|c|c|c|}
\hline Variables & LLC & Fisher-ADF & Fisher-PP \\
\hline LnT $_{\mathrm{cj}}$ & 1.286 & 123.277 & 36.212 \\
\hline LnCI $_{\mathrm{cj}}$ & 12.4359 & 54.891 & 27.337 \\
\hline LnGDP $_{\mathrm{c} G D P_{j}}$ & $-7.170^{* * *}$ & 87.417 & 412.564 \\
\hline DLnT $_{\mathrm{cj}}$ & $-15.058^{* * *}$ & $394.259^{* * *}$ & $106.336^{* * *}$ \\
\hline $\mathrm{DLnCI}_{\mathrm{cj}}$ & $-5.172^{* * *}$ & $157.109^{* *}$ & $150.282^{*}$ \\
\hline DLnGDP $_{\mathrm{c}} \mathrm{GDP}$ & & $247.568^{* * *}$ & $351.391^{* * *}$ \\
\hline
\end{tabular}

Recent literature suggests that panel-based unit root tests have higher power than unit root tests based on individual time series. Many researchers believe that it is prudent to check for unit roots in each of the time series used to estimate a model. This study conducted tests raised by Levin, Lin and Chu (2002) 
[11], Fisher-type tests using ADF and PP tests (Maddala and $\mathrm{Wu}(1999)$ [12].

Unit root tests of all series show the rejection of null hypothesis in first difference level form in the auto-regression representation of each variables by using Levin, Lin and Chu (2002) test, Fisher-type tests using ADF and PP tests.

\section{EMPRICAL RESULTS}

\section{A. Panel Cointegration Test}

For the analysis, this paper uses two types of panel cointegration test. One type of tests was introduced by Pedroni (1999) [13] and a second type was introduced by Kao (1999) which is Engle - Granger (1987) two step residual based test [14]. The results show there is a long term relationship exists within the variables.

TABLE II. PANEL COINTEGRATION TEST

\begin{tabular}{|c|c|c|c|}
\hline & & $\underline{\text { Statistic }}$ & $\underline{\text { Prob. }}$ \\
\hline \multirow{3}{*}{ Perdroni } & Panel v-Statistic & $4.892^{* * *}$ & 0.000 \\
\cline { 2 - 4 } & Panel rho-Statistic & 1.610 & 0.946 \\
\cline { 2 - 4 } & Panel PP-Statistic & $-3.445^{* * *}$ & 0.000 \\
\cline { 2 - 4 } & Panel ADF-Statistic & $-2.923 * * *$ & 0.002 \\
\hline Kao & ADF & $-2.036^{* *}$ & 0.021 \\
\hline
\end{tabular}

b. Note: ***indicate significant at the $1 \%$ level, $* *$ indicate significant at $5 \%$ level

\section{B. Model Estimation}

Hausman test are then used. The statistic of Cross-Session F-

When determining the effects of the model which include mixing effects, fixed effects, and random effects, the F-test and test was 34.9 which was significant at $1 \%$ level, showed fixed effect model was superior to the mixed regression model.

TABLE III ESTIMATION RESULTS

\begin{tabular}{|c|c|c|c|c|}
\hline Variable & Coefficient & Std.Error & t-Statistic & Prob \\
\hline $\mathrm{C}$ & $27.067 * * *$ & 2.293 & 11.804 & 0.000 \\
\hline LnInc & $0.116^{* * * *}$ & 0.039 & 2.954 & 0.004 \\
\hline $\operatorname{LnGDP}_{\mathrm{c}} \mathrm{GDP}_{\mathrm{j}}$ & $1.406^{* * * *}$ & 0.047 & 29.339 & 0.000 \\
\hline Lan & $1.391 * * *$ & 0.261 & 5.331 & 0.000 \\
\hline Bor & 0.011 & 0.072 & 1.151 & 0.879 \\
\hline APEC & $0.969 * * *$ & 0.893 & 5.463 & 0.000 \\
\hline Dis & $-2.152 * * *$ & 0.157 & -13.641 & 0.000 \\
\hline CI & $0.152 * * *$ & 0.214 & 14.331 & 0.000 \\
\hline R-squared & & 0.968 & & \\
\hline Adjusted R-squared & & 0.967 & & \\
\hline F-statistic & & $653.4 * * *$ & & \\
\hline
\end{tabular}

c. Note: $* * *$ indicate significant at the $1 \%$ level

In the choice of fixed effect model or random effect model problem, we should see whether the intercept of the stochastic model and explanatory variables are related. Hausman (1978) proposed test methods for testing. The test results showed that the probability of the chi-square statistic is more than 0.05 , accepting the null hypothesis and assuming that the equation does have a random effect.

The empirical results (Table III) showed the difference of income level (LnInc) has a significant positive impact on bilateral trade with Southeast Asia. Most of the "Belt and Road" countries are developing countries, and China is a world exporter with relative high quality and cheaper commodities which is attractive to developing countries of Southeast Asia where income levels are low. The economic scale (LnGDPcGDPj) shows a significant positive correlation in the bilateral trade.
For the culture factors, the common language (Lan), common policy institution (APEC) and Culture Intimacy (CI) have significant positive impact on bilateral trade. While distance shows the negative impact on bilateral trade. The various cultural elements play different degrees of influence on the trade. We believe that the linguistic factors among the cultural elements have played a role in promoting bilateral trade, and the above-mentioned data analysis further shows that there is a positive relationship between language factors and bilateral trade. In the context of language factors, immigration plays a key role. Oversea Chinese could spread China's historical customs and traditional cultures to the sight of foreigners, giving them a curious attitude in the process of immigration. These immigrants will also be able to see, read, and eat what they see in the countries they immigrated to. This information is passed back to the friends and relatives who are still living in China through the Internet and telephone. People want to discover the unique exotic style of the unknown 
countries. In the process of mutual understanding, people will find that the probability of trade between the two sides of the business opportunities will increase, and the trade volume of both parties may also increase. In simple terms, the cultural factors can reduce the barriers of communication between the parties in the trade process, reduce the occurrence of misunderstandings, facilitate the transmission and exchange of information, and increase the probability of occurrence of trade in general goods. The connection and tourism between China and other countries reduce the cost of information, and increases the probability of the occurrence of bilateral trade, which has played a catalytic role in the development of trade.

\section{CONCLUSION}

The "Belt and Road Initiatives" have provided great opportunities for China's bilateral trade and FDI etc. In the government's vigorous promotion of the "Belt and Road" strategy, we need to promote cultural exchanges between the two sides such as cross-border tourism and study abroad, and deliver our cultural spirits to others. To make a better understanding of each other and reduce the cultural conflicts. And we need to reduce the entry barriers and establish a fair and equitable trade platform, which can reduce transportation costs, increase the probability of trade. Therefore, based on the findings of this paper, we believes that in order to promote the trade development along the "Belt and Road" countries and to balancing the trade surplus, we should vigorously promote the construction of a cultural communication platform among countries.

\section{REFERENCES}

[1] Cohen, Shamai. (2016). A Gravity Model for Aviation Forecasting. . 10.13140/RG.2.1.1830.0401.

[2] Linnemann, Hans, 1966. An Econometric Study of International Trade Flows. Amsterdam: North-Holland.

[3] Bergstrand, Jeffrey H., 1985. "The Gravity Equation in International Trade: some Microeconomic Foundations and Empirical Evidence," Review of Economics and Statistics, volume 67, number 3, August, 474481.

[4] Soloaga, Isidro and Winters, L. Alan, Regionalism in the Nineties: What Effect on Trade? (June 1999). CEPR Discussion Paper Series Number 2183.

[5] Straubhaar, J. D. (1991). Beyond media imperialism: Asymmetrical interdependence and cultural proximity. Critical Studies in Media Communication, 8, 39-59.

[6] Zang Xin, Lin Zhu, and Shao Jun (2012). Cultural Proximity, Economic Development and Export of Cultural Products. Finance \& Trade Economics, 2012, 10: 102-110.

[7] Guiso, Luigi, Paola Sapienza and Luigi Zingales. 2009. "Cultural Biases in Economic Exchange?" Quarterly Journal of Economics, 124 (3): 1095-1131.

[8] Melitz, J., 2008. Language and foreign trade. European Economic Review 52 (4), 667-699.

[9] Wagner, D., Head, K., and Ries, J., 2002. Immigration and the trade of provinces. Scottish Journal of Political Economy 49 (5), 507-525.

[10] Rose, A., 2000. One Money, One Market, Estimating the Effect of Common Currencies on Trade, Economic Policy 30, 7-45.

[11] [5]Levin, A., C.-F. Lin, and C.-S. J. Chu. 2002. Unit root tests in panel data: Asymptotic and finite-sample properties. Journal of Econometrics 108: 1-24.

[12] [6]Im, K. S., M. H. Pesaran, and Y. Shin. 2003. Testing for unit roots in heterogeneous panels. Journal of Econometrics 115: 53-74.

[13] Pedroni, Peter (1999) "Critical Values For Cointegration Tests in Heterogeneous Panels With Multiple Regressors”, Oxford Bulletin of Economics and Statistics 61, 653-670.

[14] Kao, Chihwa (1999) "Spurious Regression and Residual-Based Tests for Cointegration in Panel Data", Journal of Econometrics 90, 1-44. 